\title{
Cyclophosphamide/Trastuzumab Regimen
}

National Cancer Institute

\section{Source}

National Cancer Institute. Cyclophosphamide/Trastuzumab Regimen. NCI Thesaurus.

Code C156365.

A chemotherapy regimen consisting of cyclophosphamide and trastuzumab that may be used in the treatment of HER-2 (EGFR2; ErbB2)-positive breast cancer. 